\title{
Influence of Individual Learning Styles in Online Interaction: a Case for Dynamic Frequently Asked Questions (DFAQ)
}

\author{
Dick Ng'ambi \\ Centre for Educational Technology, University of Cape Town, P/b \\ Rondesboch, Rondesboch, Cape Town, South Africa 7700 \\ dngambi@ched.uct.ac.za WWW home page: http://www.cet.uct.ac.za
}

\begin{abstract}
Although current literature on learning styles shows that matching a teacher's instructional style with the learning styles of students affects performance in a classroom environment, little is known about the influence of learning styles in online interaction. The paper argues that students' individual learning styles influences how students interact online and that rather than adapt to user's learning styles, online environments tend to force behavior change on users' learning styles. The paper discusses a project in which students with varying learning styles used an online consultation (DFAQ) tool for collaborative knowledge sharing, and reports on how learning styles influenced online interaction and the use of DFAQ changed rather than adapted to users' learning styles. The paper concludes that for online environments to be educationally efficacious, sensitivity to different learning styles is desirable though the implementation of such sensitivity is non-trivial.
\end{abstract}

\section{Introduction}

While technologies are increasingly used as teaching and learning tools, not much is known about how users adapt their learning styles when using technology and how technologies may adapt and change to meet diverse learning styles of users. Although online learning environments "provide an environment for differing learning styles" [1], working in online environments requires that learners "change behavior" [2], and different learners follow different "patterns of learning" [3]. It seems reasonable that understanding how students' learning styles influence patterns of online learning would lead to designs of "equitable" [1] and "culturally inclusive" 
[24] learning environments. Learning styles have been associated with cultural inclusion [1], cultural amplification [25], belief systems [25], social values [10] and academic performance [5][20] but the influence of learning styles on how learners interact online has not been investigated; hence this paper. The Internet is reported to affect learner-teacher relation [23], and online conversation affects dialogue [21] thereby influencing interaction and learning style. In this paper, learning is used in Argyris' way which is "the detection and correction of error. An error is any mismatch between our intentions and what actually happens" [8]. It follows that a learning style is a technique used by a learner to detect and correct his/her own misconceptions or misunderstandings. The paper does not distinguish learning styles from "learning preferences and learning strategies" [9], as these tend to converge in an online interaction.

The rest of the paper is organized as follows: section 2 and 3 discuss why the project focused on online interaction driven by questions and related work, respectively; section 4 discusses the theoretical framework which provides lenses used to analyze the artifacts of online interaction; in section 5 the methodology including the case study is described; findings are discussed in section 6 and the conclusion in section 7 .

\section{Focus on questioning}

We also can't learn without asking questions, and merely recognizing that an object is different, and not as we first thought, presupposes the question whether it was this or that [11]. A child who asks questions about fire would have a richer and broader learning experience, including the purposes of fire, its dangers, and its benefits, when it is used and how; than one who asks no question but only touches.

In online consultation "textual meaning is not viewed simply as an assertion about a state of affairs but as something to be responded to" [12]. Text is an invitation for discourse. To ask a question (text) is to bring whatever is in question "into the open" [11]. A question is therefore a vehicle through which its contents are brought into the open. However, what exactly is brought into the open, in what way it is brought into the open, and the depth with which it is brought into the open differ depending on individual learning styles. Thus the focus on questioning was partly motivated by the need to teach students questioning skills and use of questions as an online conversation catalyst to foster knowledge sharing among peers.

\section{Related work}

Miller's [5] study compared two instruments, the Gregory Style Delineator and the Kolb Learning Style Inventory, while evaluating the effects of learning styles on performance when using computer-based instruction system; Montgomery [6] investigated ways in which multimedia can be used to address the needs of a variety of student learners; Liu and Reed [7] measured patterns of learning by the frequency of student access to different functions in a hypermedia environment. Some of the 
instruments used to measure learning styles include: Honey and Mumford's Learning Styles Questionnaire [15]; Direktor's Learning Style Instrument [16]; Soloman's Inventory of Learning Styles [6]; and the Group Embedded Figures Test [3]. None of this work focuses on online interaction, and influence of learning styles has not been applied to self reporting empirical materials.

\section{Theoretical framework}

An investigation of learning styles in online interaction is sandwiched between individual approaches to learning on one hand and technology mediation on the other hand. There are two approaches taken to unravel and gain insight into the phenomenon. We gathered data on individual learning styles through self reporting. Analysis of online interaction was achieved through artifact (content) analysis. The tertiary goal of artifact analysis is to determine whether users of different learning styles ask different types of questions and in what ways does a mediating medium shape learning styles? The challenges lie in finding evidence [10] of learning styles from online artifacts. The word "evidence" is used loosely in that an interpretive research paradigm is applied.

Thus, rather than attempting to extract evidence from artifacts, we sought to use self reporting as an evidence base. The underlying thesis in this paper is that in online interaction the way that users process and post messages and the meanings that get associated with the messages alter individual learning styles and influence online interaction. To investigate this, McLoughlin's [9] forms of information presentation to match cognitive style were adapted because of their focus on processing and conceptualization of information. McLoughlin [9] postulates four forms of information presentation to match cognitive styles:

Table 1: Forms of information presentation to match cognitive style

\begin{tabular}{|c|c|c|}
\hline Style & Learner characteristics & Text presentation \\
\hline Wholists & Tend to see the situation as a whole & $\begin{array}{l}\text { Advance organizer to } \\
\text { indicate parts and } \\
\text { structure of material }\end{array}$ \\
\hline Analytic & See collection of parts & $\begin{array}{l}\text { Overview to provide } \\
\text { a picture of the whole }\end{array}$ \\
\hline Verbalisers & $\begin{array}{l}\text { Represent knowledge verbally } \\
\text { (speech and text) }\end{array}$ & $\begin{array}{l}\text { Verbal versions of } \\
\text { pictorial material }\end{array}$ \\
\hline Imagers & $\begin{array}{l}\text { Represent knowledge } \\
\text { pictorially (images) }\end{array}$ & $\begin{array}{l}\text { Pictorial form verbal } \\
\text { material }\end{array}$ \\
\hline
\end{tabular}

McLoughlin argues that this categorization is useful as it suggests that learners differ in terms of two fundamental dimensions:

(a) Wholist-Analytical: this dimension describes how individuals process information. Analysts tend to process information into component parts, while wholists prefer to keep a global view of the topic. 
(b) Verbaliser-Imager: this dimension describes how individuals represent information during recall. Thus, verbalisers tend to present information in words, while imagers tend to present information in pictorial form.

Accepting McLoughlin's two fundamental learner dimensions, it follows that learners interact online differently and that the tool of interaction may have varying impact on interaction depending on a learner's cognitive style and the learner's interpretive logic of dialogue. An interpretive logic of dialogue in "the creative play of question and answer, whereby what is stated about the subject matter may be understood productively as an answer to a question" [12].

\section{Case study description}

In this study, honors students in a semester course in Organizational Learning at the University of Cape Town (UCT) engaged in an online knowledge-sharing experience. UCT is a medium-sized contact institution and ICTs (Information and Communication Technologies) form an important part of teaching and learning but do not necessarily dominate the contact character. Students in the honors class were from diverse socio-historical, cultural and economical backgrounds. In view of this, the class had learners with multiple learning styles, the diverse backgrounds meant rich and diverse opinions, came from multiple locations (were not all resident on campus) and used different mediating tools for communication (such as networked computers and cell phones). Learning tasks were designed to encourage collaborative learning. Dynamic frequently asked questions (DFAQ) was a medium of interaction.

DFAQ is an asynchronous knowledge sharing tool [18] whose artifacts provide insight into how students detect and correct errors through anonymous posting of questions and responses. Sims [19] rightly observes that little is known about the way people learn with technology and therefore there is no guarantee that creation of an automated complex interaction would accurately adapt to the individual student's learning styles. DFAQ (see Figure 1) served as a medium through which students accessed a shared information resource created from artifacts of interaction. The users post questions using a web interface or the SMS from their mobile phones. The artifacts (questions and responses) of interaction become visible to other students who lookup or reference the resources (questions and responses).

At the end of the semester (six-month course), students were invited to volunteer to be part of a focus group to discuss their learning styles and their experience with the DFAQ knowledge sharing tool. This approach is pragmatic in view of other studies that used psychometric tests [9] and questionnaires [3]. 
Figure 1. DFAQ User Interface

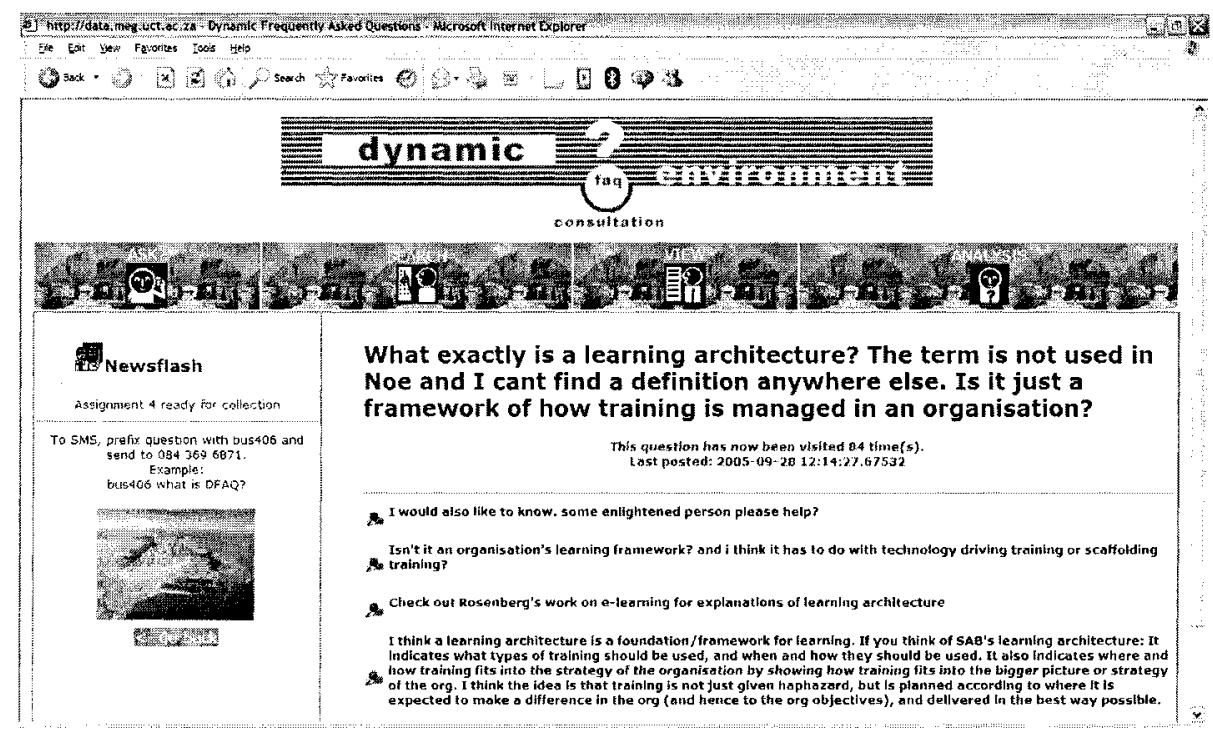

\section{Findings and discussion}

This section is divided into two parts. The first part analyses transcripts from a focus group in which learners reported on their individual learning styles. The focus group discussion was held after a six month session in which learners engaged in an authentic online knowledge sharing activity. In the second section, an analysis of the influence of the tool on online interaction is presented.

\subsection{Learning styles and information presentation}

Our assumption was that student forms of information presentation (mental process) influences online interaction (outward actions). Following an online experience, we asked students a self-reflection question on how they generally learn. One student said:

a) I found in school I learnt to practice cross reference, cross reference, cross reference, now if I can see something from a map review and I can almost picture what we study but in the sections in my mind and I understand it much better and also with colour - in my notes with colour because I can picture the colour in my head and I am thinking about that and in terms of honours I found it great in terms of understanding what you have learnt in application

The above statement suggests that the student is a wholist (inferred from a "map review") and advance organizer (suggested by cross referencing). The use of colors for representation shows that the learner is an imager. A similar learning style was mentioned by another student: 
b) I am a colour child, I love highlighting everything I learn in colour and in pictures and mind maps are the best, if I can see an overview of what the material is that I need to learn it is fantastic, picture it and remember it and regurgitate it at any time.

Suggested in the words "mind maps are the best" and "overview" is that the learner is a wholist. Another student reported that,

c) I am quite an open learner, I do a lot of research, I love reading so I go and get lots of information and I try to sort it out in my brain and do discussions with people.

In this statement the student uses discussions with people as a means of filtering information gather from research. This "filterist" approach is not one of McLoughlin's categories as the student in this case is a late organizer as opposed to advance organization. However, the "doing of discussions with people" suggests a verbaliser learning style. Another learning style that did not fit neatly in the McLoughlin's categories was a "practical" learning style.

d) I have always been a very practical person so I like to apply what I learn to different parts of my life or be able to make associations with what I am learning in other areas of my life, otherwise I really struggle to just understand concepts without having some practical application.

For a "practicalist" the need for practical application of knowledge is critical and it's the application that provides the structure in which text is represented. However, sorting information in ones brain (see student comment (c)), presumes that a student has memory. The problem is that not every student has memory as this student testifies:

e) I have a strange way of learning because I have no memory whatsoever. I have to read everything until it is common sense to me. I read anything that I can get my hands on and eventually the things start making sense in terms of the assignment that we have to do, those are the kinds of things that I can remember, everything else should go... I can't make notes... I don't have a memory so it is very much just read until it is general knowledge and work from there and also keeping things organised in my head.

The assignment is used as a structure base and the "reading until it is common sense" could be a way the student sees the collection of readings becoming part of a picture of the whole. This approach indicates that a student is an analytic. This is how one student said works for her/him:

f) And also reading and writing, not just reading in isolation but writing it down even if it is just scrap notes, just to write it down is a second way of getting it through your brain and then I also find that I compartmentalise my learning and my courses which is great for an organised point of view but also I find for me I tended to sometimes lose sight of a bigger picture and that all the six courses that we have done are all tied together and sometimes you lose sight of those links.

The learning approach of writing down and compartmentalization of learning suggests the treatment of information as a collection of parts hence an analytic style. Taking notes is a form of interrogation of text and the learner is therefore a type of Verbaliser. While note taking works for some learners others adopt approaches that would help them forget. 
g) I think I am quite a strange learner because I like to get as much information as possible and then try to decide what I need so I get everything, I read everything I can, I cram it all in and then I decide what is important and I forget what is not important and I only take what is important - I keep the important parts if it is very important.

Although the learner is assumed to have a reference point in determining what could be important, the fact that the learner deliberately chooses to forget is an important characteristic. Thus, this "forgetist" learning style does not fit in any of McLoughlin's categories.

In the next section we discuss how a mediating tool (DFAQ) influenced learning styles.

\subsection{Effect of DFAQ interaction on learning styles}

The underlying premise of this section is that a mediating tool (DFAQ) models behavior of users in ways that influences learning styles. Students reported adapting their learning styles to fit with the design of the tool. One student compared face-toface interaction with DFAQ mediated interaction as follows:

h) I found that you had to express yourself quite clearly because when you are in a conversation, the person will say to you that they do not understand the question or can you say more, you have got to put everything out there straight away and make your questions as clear as possible so that they know exactly what you are asking instead of just like "can you help."

The statement suggests that DFAQ encouraged learners to "put everything out there straight away" whereby fostering advance organization of thoughts (suggesting that a tool modeled an Analytic learning style). The realization of a need to post messages with a reader in mind suggests an inclination towards "conversation" further implying that DFAQ may have orientated learners towards a Verbaliser learning style.

i) I think sometimes you feel like you can't express it properly... it will be too much of a conversation, too long rather and also I thought I would not be able to express it properly.

As a text based tool, interaction for learners who use pictures in their learning styles may have found it difficult to effectively communicate in text. The use of text created artifacts which other learners accessed and this may have impacted on learners who are wholists as they needed to understand a big picture before making a contribution.

j) grabbing all kinds of ideas, thinking about them, still thinking how I can interlink them and how they make a picture and how they apply, you see I am still in the process of doing this, so in other words to ask a question about all these different thoughts that I have, to ask one question, it is difficult because I am still in the process of forming my opinion, forming my ideas, so I did not find like I could ask what I wanted to ask sometimes.

While access to a deluge of information could have created difficulties for this learner, other learners (see $(\mathrm{g})$ ) found this useful depending on the learning style. It 
appears that Wholistic learners may have tended to post few messages but well thought out messages as time was spent "in the process of forming opinions".

k) there were so many responses towards the end that you get more used to it, more people use it, you get comfortable with it and the more that you use it...

Reference to "...more people use it... the more that you use it" suggests that through the provision of access to the way other students asked questions, DFAQ had influenced the online interaction and strategies of learning. Although learning styles are individualistic, access to peers' thought processes provides a way of self detection and correction of misconceptions or misunderstandings. Hence DFAQ provided a way of affirming students through passive engagement (lurking and reading a deluge of postings) and by active engagement (posting questions and receiving responses from peers). A student reported that,

l) $D F A Q$ is a very nice resource for me in the Organizational learning filing cabinet I could use that resource to add to my learning. It is almost like when I need it -when you need to be affirmed in what you are doing because often I felt like $I$ did quite independent stuff - I would get all this information and then I would go to DFAQ - and say "OK I am on the right track or No I am going down the garden path" - so it was a nice resource in that way.

It can be inferred from the above statement that DFAQ modeled behavior of learners into a particular way regardless of their individual learning styles. The external factors, such as deadlines, may also influence the learning styles. McLoughlin's forms of information presentation do not acknowledge the impact of context and environmental factors on learning styles.

m) I was driven by panic because it would often be a question that would be related to something that we would have to hand in so it would be a panic stricken question - "O my word - how many pages - can we do this - can we that - is it alright to this - it is alright to do that."

Another external factor is that of the confidence that learners have in the medium of interaction and the community (peers).

n) I think of the six months that we have used it people were getting more and more comfortable with it and using it more freely to the point where near the end students were replying to students questions and I think that if it was a resource that we had maybe for 12 months it probably would have gotten to a more interactive point...

Suggested in the comment "... would have gotten to a more interactive point" is that DFAQ may have influenced learning styles.

\section{Conclusion}

In this paper we set out to show that the way that different individual learners interact online is partly influenced by individual learning styles, and that the medium of interaction or the mediating tool shapes online interaction, hence modeling behaviour of users. To investigate this phenomenon, a text-based anonymous tool facilitated online interaction in a six-month course. Learners reported on their own learning styles and how they experienced the online engagement. McLoughlin's 
forms of information presentation to match cognitive style were used to guide an interpretive analysis because of their distinction between learner characteristics as embodied in the mental state and text presentation as an outward act. The paper has shown that some learning styles (for example, the "practicalist", "filterist", and "forgetist") could not neatly fit in McLoughlin's taxonomy. It has also shown that while some features of the tool may have effectively supported certain learning styles, other learners adapted their learning to the way the tool was designed. It can be inferred from the diversions of learning styles that learning style is a complex phenomenon and could be dynamic depending on context. One of the design challenges of learning environments is how to design for diversity of learning styles and understanding the impact of design choices on various learning styles.

Finally, we make the following recommendations:

- Online interaction requires that a sender construct messages in ways that allow the receiver to understand. A user's learning style influences online interaction and determines whether a user is likely to be an active or passive participant. Design of tools ought to cater for users who need detailed information, summaries, text formats and visual representations. Providing windows to information in these various forms would serve the needs of diverse learning styles.

- Learning styles are complex social phenomena which cannot be categorized using superficial and deterministic taxonomies. Learning styles analysis should form part of user requirement.

- An online mediating tool is not neutral but models learners' behavior including how learning styles are used to accomplish tasks. Systems or tools are usually embodied with design biases and preferences. Successful mediation of online interaction presupposes that individual styles are provided for, if they are to be successful.

- Taking recognizance that students learn differently whether online or face-toface and that a single pedagogical design cannot fit all learning styles should lead to designs of online learning environments that are educationally efficacious. Further research is required on the effect of social awareness in online learning styles.

\section{References}

1. Blum, D. K. Gender Differences in Asynchronous Learning Higher Education: Learning Styles, Participation Barriers and Communication Patterns. JALN, Vol. 3. No. 1. 1999. Accessed at http://blogs.usu.edu/students/stacie.gomm/archives/BlumArticle.pdf

2. Sheard, J., Ramakrishnan, S. and Miller, J. Modelling learner and educator interactions in an electronic learning community. Australian Journal of Educational Technology. Vol. 19. No. 2. 2003. pp. 211-226

3. Lu, J. Yu, C. and Liu, C. Learning style, learning patterns, and learning performance in a WebCT-based MIS course. Information \& Management. Vol. 40. No. 6. 2003. pp. 497 507

4. Leopold-Lusmann, D, B. Virtual Learning Environments and Student Learning Styles. 2000. 
sb.de/pub1/ss00/seminar/ss2000/int/individualwork/uploads/238/IndividualAssignmentHe atherWilliams.htm

5. Miller, L. M. Using learning styles to evaluate computer-based instruction. Computers in Human Behavior. Vol. 21 No. 2, 2005, pp. 287-306.

6. Montgomery, S. M. Addressing Diverse Learning Styles through the Use of Multimedia. 1995. Accessed at: http://fre.www.ecn.purdue.edu/FrE/asee/fie95/3a2/3a22/3a22.htm

7. Liu, M. and Reed, M. W. The relationship between the learning strategies and learning styles in a hypermedia environment. Computers in Human Behavior. Vol. 10. No. 4. 1994. pp. 419-434.

8. Argyris, C. On Organizational Learning. Massachusetts: Blackwell Publishers, 1992.

9. McLoughlin, C. The implications of the research literature on learning styles for design of instructional material. Australian Journal of Educational Technology. Vol. 15. No. 3, 1999. pp. 222-241. http://www.ascilite.org.au/ajet/ajet15/mcloughlin.html

10. Naidu, S. and Jarvela, S. Analyzing CMC content for what? Computers \& Education. Vol. 46. No. 1. 2006. pp. 96-103

11. Bontekoe, R. Dimensions of the Hermeneutic Circle. New York: Humanity Books, 2000

12. Kogler, H. H. The Power of Dialogue. Hendrickson P (trans), London: MIT Press, 1996

13. Carr, W. and Kemmis, S. Becoming Critical: Education, Knowledge and Action Research. Victoria, Austrialia: Deakin University Press, 1986

14. Cherryholmes, H. C. Power and Criticism, New York: Teachers College Press, 1988

15. Honey, P. and Mumford, A. The Manual of Learning Styles. Maindenhead: Mazhar Honey. 1992.

16. Direktor, D. A. Experiential learning: experience as the source of learning and development. Englewood Cliffs, NY: Prentice-Hall. 1984

17. Strijbos, J., Martens, L. R., Prins, J. F. and Jochems, M. G. W. Content analysis: what are they talking about? Computers \& Education. Vol. 46. No. 1. 2006. pp. 29-48

18. Ng'ambi, D. and Hardman, J. Towards a knowledge-sharing scaffolding environment based on learners' questions. British Journal of Educational Technology, 35(2). 2004. 187-196

19. Sims, R. C. H. Interactive learning as an "emerging" technology" A reassessment of interactive and instructional design strategies. Australian Journal of Educational Technology. Vol. 13. No. 1, 1997. pp. 68-84

20. Cho, H., Gay, G., Davidson, B. and Ingraffea, A. Social networks, communication styles, and learning performance in a CSCL community. Computers \& Education, 2005 [in press]

21. Burbules, C. N., and Bruce, C. B. Theory and Research on Teaching as Dialogue. 2001. Accessed at: http://faculty.ed.uiuc.edu/burbules/ncb/papers/dialogue.html

22. Abbas, S. 'Transformative' Models for Learning, Teaching and Academic Professional Development - A 'Self-ish' Approach. Learning \& Teaching in Action. Vol. 2 No. 2. 2003. Accessed at: http:/www.ltu.mmu.ac.uk/ltia/issue5/abbas.shtml

23. McLoughlin, C. and Oliver, R. Designing learning environments for cultural inclusivity" A case study of indigenous online learning at tertiary level. Australian Journal of Educational Technology. Vol. 16. No. 1, 2000. pp. 58-72. 2000. Accessed at: http://www.ascilite.org.au/ajet/ajet16/mcloughlin.html

24. Cole, $M$. The zone of proximal development: Where culture and cognition create each other. In J. V. Wersch (ed.), Culture and cognition: Vygostkyan perspective. Cambridge: Cambridge University Press. Pp. 146-161.

25. Chen, A., Mashadi, A., Ang, D., and Harkrider, N. Cultural issues in the design of technology enhanced learning systems. British Journal of Educational Technology, Vol. 30. No. 3. 1999. pp. 231-245 